\title{
Non-antibiotic treatment recommendations: delivery formats and implications for parent resistance
}

\author{
Tanya Stivers* \\ Max Planck Institute for Psycholinguistics, Language and Cognition Group, PB 310, 6500 AH Nijmegen, Netherlands
}

Available online 28 September 2004

\begin{abstract}
This study draws on a database of 570 community-based acute pediatric encounters in the USA and uses conversation analysis as a methodology to identify two formats physicians use to recommend non-antibiotic treatment in acute pediatric care (using a subset of 309 cases): recommendations for particular treatment (e.g., "I'm gonna give her some cough medicine.") and recommendations against particular treatment (e.g., "She doesn't need any antibiotics."). The findings are that the presentation of a specific affirmative recommendation for treatment is less likely to engender parent resistance to a non-antibiotic treatment recommendation than a recommendation against particular treatment even if the physician later offers a recommendation for particular treatment. It is suggested that physicians who provide a specific positive treatment recommendation followed by a negative recommendation are most likely to attain parent alignment and acceptance when recommending a non-antibiotic treatment for a viral upper respiratory illness.
\end{abstract}

(C) 2004 Elsevier Ltd. All rights reserved.

Keywords: Conversation analysis; Doctor-patient communication; Antibiotic prescribing; Pediatric care, USA

When people seek medical attention for an illness, they are generally looking for both an explanation of the illness and for a solution to their/their child's medical problem (Robinson, 2003). Prior research has documented that acute medical encounters typically include a phase of the interaction that is concerned with treatment (Byrne \& Long, 1976; Robinson, 2003; Waitzkin, 1991). However, little attention has been paid to the ways in which treatment recommendations are formulated or to the alternative types of responses patients/parents provide to these delivery formats. Upper respiratory tract infections (i.e., colds, flu, throat, ear, or sinus infections) constitute the most common reason parents seek medical care for their children (Rotbart \& Hayden, 2000). Such infections are typically either bacterial

\footnotetext{
*Tel.: + 31-24-3521408; fax: + 31-24-352-1213.

E-mail address: Tanya.Stivers@mpi.nl (T. Stivers).
}

(treatable with antibiotics) or viral (treatable only symptomatically) (e.g., $84 \%$ of total sample for this study were viral or bacterial as reported in MangioneSmith et al., 2004). Physicians and parents alike can be observed to orient to these alternations as they emerge in problem presentation and history taking (Stivers, 2000) and in the physical examination (Heritage \& Stivers, 1999). Thus, the provision or denial of antibiotics is common during the treatment recommendation phase of these visits. This paper will focus on the different ways that these recommendations are formatted.

Treatment decisions in the context of pediatric upper respiratory infections (URIs) are particularly important currently. Although the US, along with many other developed nations, is facing a large-scale problem with antibiotic resistant bacteria (Baquero, Baquero-Artigao, Canton, \& Garcia-Rey, 2002; McCaig \& Hughes, 1995; Neu, 1992; Reichler et al., 1992; Schwartz, 1999; 
Whitney et al., 2000; Wise et al., 1998), inappropriate prescribing of antibiotics for viral infections is common (Finkelstein et al., 2000; Gonzales, Malone, Maselli, \& Sande, 2001; Gonzalez, Steiner, \& Sande, 1997; Mainous, Hueston, \& Clark, 1996; Mangione-Smith et al., in press; McCaig, Besser, \& Hughes, 2002; Pennie, 1998). Inappropriate use of antibiotics has led to rapidly increasing risks of resistance among many strains of bacteria that commonly infect children and adults (Cristino, 1999; Deeks et al., 1999; Gomez et al., 1995; Nava et al., 1994; Watanabe et al., 2000). Resistant infections pose a risk not only to the individual but also to the community because those infections are more difficult to treat (Dagan, 2000; Friedland, 1995; Watanabe et al., 2000), more costly (Gums, 2002; Holmberg, Solomon, \& Blake, 1987), and result in increased mortality (Feikin et al., 2000). For all of these reasons, researchers and policy makers are strongly advocating for more judicious prescribing practices (e.g., Bell, 2002; Belongia et al., 2001).

In pediatrics, $65-70 \%$ of upper respiratory tract infections are viral (Wald, Guerra, \& Byers, 1991) and thus cannot be effectively treated with antibiotics (Kaiser et al., 1996; Orr, Scherer, MacDonald, \& Moffatt, 1993; Todd, Todd, Damato, \& Todd, 1984). However, current research shows that the prescribing rate for viral colds across populations is nonetheless still $30 \%$ (Gonzales et al., 2001). Prescribing for bronchitis and other illnesses that are typically of viral origin are estimated to be as high as $60 \%$ (Gonzales et al., 2001). Within pediatrics, between $48 \%$ and $65 \%$ of parents visiting report an expectation that their child will be given antibiotics (Hamm, Hicks, \& Bemben, 1996; Mangione-Smith et al., in press; Mangione-Smith, McGlynn, Elliott, Krogstad, \& Brook, 1999; SanchezMenegay \& Stalder, 1994). Results from the National Ambulatory Medical Care Survey show that children receive 2-4 times more antibiotic prescriptions than any other patient group including the elderly (Aronoff, 1996). Thus, overuse in the pediatric population poses the greatest risk to the community as a whole.

Physicians' continued over prescription of antibiotics appears to be strongly related to patients' and parents' pressure on doctors for a quick solution to their problem. Research has shown that parent pressure is commonly cited by physicians as a reason for prescribing (Barden, Dowell, Schwartz, \& Lackey, 1998; Palmer \& Bauchner, 1997; Schwartz, 1999; Schwartz, Freij, Ziai, $\&$ Sheridan, 1997). Several communication practices used by parents appear to be what actually constitutes "pressure" (Stivers, 2002a, b, in press; Stivers, Mangione-Smith, Elliott, McDonald, \& Heritage, 2003). For instance, and of particular relevance for the present study, if a parent offers "resistance" to a non-antibiotic treatment recommendation, physicians are significantly more likely to perceive that the parent expects anti- biotics (Stivers et al., 2003). ${ }^{1}$ In turn, when a physician perceives a parent to expect an antibiotic, they are more likely to prescribe an antibiotic even if it is not clinically appropriate (Mangione-Smith et al., in press, 1999; Vinson \& Lutz, 1993).

Focusing on cases that involve the delivery of nonantibiotic treatment recommendations, ${ }^{2}$ this paper first identifies and examines two alternative practices through which physicians deliver their treatment recommendations: (1) recommendations for a treatment and (2) recommendations against a treatment. Second, it examines parent responses focusing on parent resistance to non-antibiotic treatment recommendations to investigate how the two formats are understood by parents. Finally, it examines apparently deviant cases to inform a claim that one recommendation format is better suited to the delivery of non-antibiotic treatment recommendations.

\section{Data and method}

The data for this study are video-taped interactions of community practice pediatricians in encounters with parents and children seeking medical attention for upper respiratory illness symptoms (sore throats, fevers, ear pain, nasal congestion, and cough). None had been given antibiotics in the prior 2 weeks. A total of 38 pediatricians from 27 pediatric practices (64\% participation rate) and 540 parents and children $(83 \%$ participation rate) participated in the study which took place between October 2000 and June 2001. For these analyses, I will be focusing on a subset of 309 cases where the treatment being recommended was not antibiotics. All physician and parent participants gave written informed consent. All study procedures were reviewed and approved by the UCLA General Campus Institutional Review Board (IRB).

Data were analyzed relying on conversation analysis to identify recurrent physician practices of communication and patterns of parent response to physician

\footnotetext{
${ }^{1}$ Here, when I refer to "resistance", I mean "active resistance". In the context of a physician's recommendation for treatment, active resistance is intended to encompass behavior that not only fails to align with the physician's recommendation - passive resistance - but also initiates a sequence of action regarding the treatment such as a challenge, queries about the effectiveness or appropriateness of the medication or about alternative treatments (Stivers, in press).

${ }^{2}$ This paper focuses only on non-antibiotic treatments in order to avoid the conflation of antibiotics and recommendation format. Since antibiotics are virtually always delivered using the format "recommendation for" and further since they are almost never resisted, the importance for understanding the differential use of formats was among non-antibiotic recommendations.
} 
practices (for a review see Heritage, 1984b). As summarized in earlier work on these types of data (Stivers, 2002a, b), CA examines the social actions that interactants accomplish in and through interaction focusing on sequences of interaction (e.g., the delivery and reception of advice in British health visitors' interactions with first time mothers (Heritage \& Sefi, 1992), the delivery and receipt of diagnoses (Heath, 1992; Peräkylä, 1998), and the delivery and reception of bad news (Maynard, 2003) rather than restricting analyses to isolated sentences or phrases (for a full discussion see Schegloff, in press).

In examining social interaction, CA looks for patterns in the interaction which form evidence of systematic usage that can be identified as a "practice" through which people accomplish a particular social action vocally or visibly. To be identified as a practice, a particular communication behavior must be seen to be recurrent and to be routinely treated by recipients in a particular way such that it can be discriminated from related or similar practices. Central to this procedure is that analysts' understandings of participants' social actions can be validated through an examination of interactants' responses. The significance of practices can be understood in terms of (1) the immediate sequences in which they occur (e.g., Pomerantz, 1984), (2) the larger activities in which they are embedded (Heritage \& Sorjonen, 1994), and (3) the overall organization of the phases in the interaction (Drew \& Heritage, 1992b). The latter two levels of organization are of particular significance when CA is used to analyze interaction in institutional contexts because in many of these contexts, the participants are oriented to an overarching goal/task which is often accomplished through an extended course of interaction embodying many sequences and phases (Drew \& Heritage, 1992b).

Utilizing CA as a primary methodology, this study examines physician-parent interactions in detail to observe the interactional resources physicians and parents use to negotiate a decision of whether or not to prescribe antibiotics for a child with upper respiratory symptoms. The cases that will be discussed below were selected because they represent especially clear examples of the phenomena. Unless it is stated otherwise, the examples are of initial treatment recommendations. In most cases, a diagnosis was provided earlier. However, in some cases a diagnosis may have been implied "online" through the negation of various problems (e.g., "No ear infection" while looking at the ears) (Heritage \& Stivers, 1999), or it may be delivered as an account for the initial treatment recommendation. ${ }^{3}$

\footnotetext{
${ }^{3}$ Results of quantitative analyses will be reported elsewhere.
}

\section{Analysis}

\section{Background}

Stivers (in press) showed that the normative structure of the treatment recommendation activity was such that parent acceptance was due upon completion of the physician's initial treatment recommendation. Moreover, if it was not forthcoming, physicians routinely pursued, or did interactional "work" to secure, this acceptance (see Fig. 1). Further, in the absence of any change in the physician's treatment proposal, parents displayed that a lack of response was indeed a form of passive resistance by frequently upgrading to active resistance (see Heritage \& Sefi, 1992; Stivers, in press for a discussion of passive vs. active resistance). Similar to previous work on preference structure (e.g., Pomerantz, 1984; Sacks, 1987), even a very small silence following a treatment recommendation is oriented to by physicians as indicating incipient disagreement and, not infrequently, preceded physicians' concessions to parents (Stivers, in press).

Given the research reviewed earlier in this paper that showed resistance to be associated with physician perceptions of parent expectations for antibiotics, the question to be addressed here is whether or not the way that physicians deliver their treatment recommendations promote or retard parent resistance to the recommendation. Although prior studies that examined treatment recommendations have included both examples of treatment recommendations that are formatted for particular therapies, and those that are formatted against particular therapies as instances of treatment recommendations in acute care encounters (Byrne \& Long, 1976; Robinson, 1999; Waitzkin, 1991), I will argue that there are important reasons for distinguishing between the two delivery formats. ${ }^{4}$ In what follows I will first describe the two primary recommendation formats that I have observed. Second, I will discuss what constitutes a "sufficient" treatment recommendation as evidenced by the interactions. I will argue that it is this that underlies the differential responses parents' provide to recommendations for vs. against particular treatment. Finally, I will outline some of the implications of this

\footnotetext{
${ }^{4}$ Waitzkin (1991) did note that there was a difference between recommendations for and against particular treatment. With respect to differentiating between these two formats, he states that "a doctor may suggest non-intervention, which includes reassurance that the problem is not serious enough to require technical action, or a schedule of follow-up to be sure that the problem does not become worse" (p. 32). However, he does not examine the structural differences between the two formats, the implications of the formats for patient behavior, nor does he discuss the potential uses of one format vs. another. He does though show that both recommendations for and against particular treatment occur in the adult primary care context.
} 


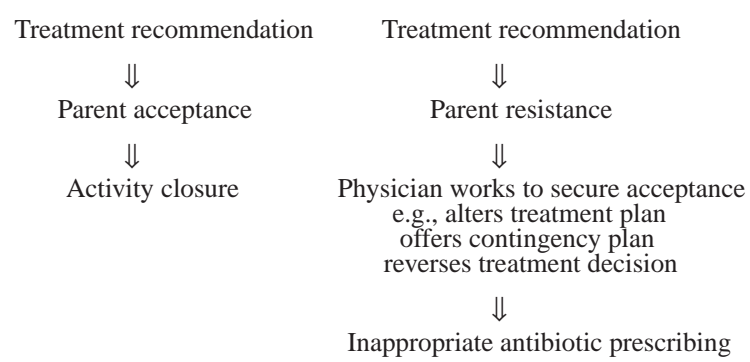

Fig. 1. Structure of the treatment recommendation.

work for treatment recommendation delivery in primary care encounters particularly with respect to the ordering of these alternative treatment recommendation formats.

\section{Recommendations for a particular treatment regimen}

The most common delivery format for treatment recommendations is for the physician to affirmatively suggest what should be done for the patient's problem. Of the 309 visits examined for this study, this format was used for the first recommendation in 252 cases $(82 \%))^{5}$ As an example, Extract 1.

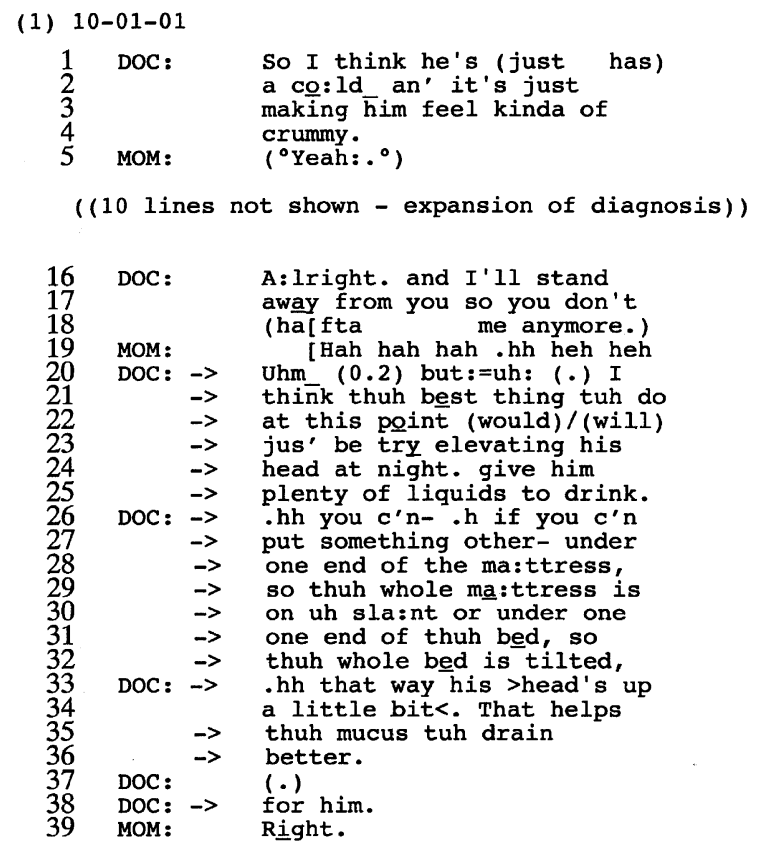

\footnotetext{
${ }^{5}$ This paper focuses on initial treatment recommendations in large part because the provision of additional recommendations is very much a product of the interaction. While this is interesting in and of itself, here I was primarily interested in the consequence of the format of the first recommendation on immediately subsequent behavior.
}

Here, the physician offers her diagnosis in lines 1-4. After providing some evidence for this in terms of the fever (data not shown) she outlines the treatment she recommends for the boy in lines 20-38. The physician's recommendation is framed as a recommendation of what should be done: elevating the boy's head at night and giving him plenty of liquids. Although there is no medication being recommended, the treatment recommendation is nonetheless formatted affirmatively. A second example is shown in Extract 2. Similar to Extract 1, here too a diagnosis of a cold was provided just previously (data not shown). The treatment begins at line $1 .^{6}$

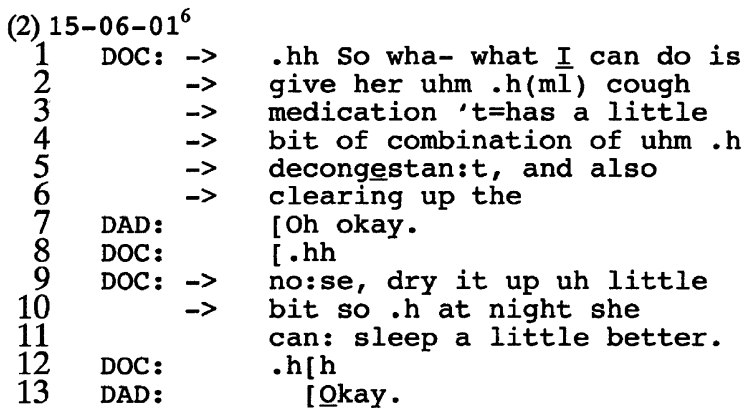

The physician affirmatively proposes cough medicine which has decongestant in it. This is accepted by the father first in line 7 and then in line 13. Note that the first acceptance is possibly placed a bit late relative to "decongestan:t," and this may account for the "Oh" preface which registers the import with "clearing up" (Heritage, 1984a). A final example is shown in Extract 3. Once again a diagnosis of a cold was offered (data not shown). The treatment begins at line 1 .

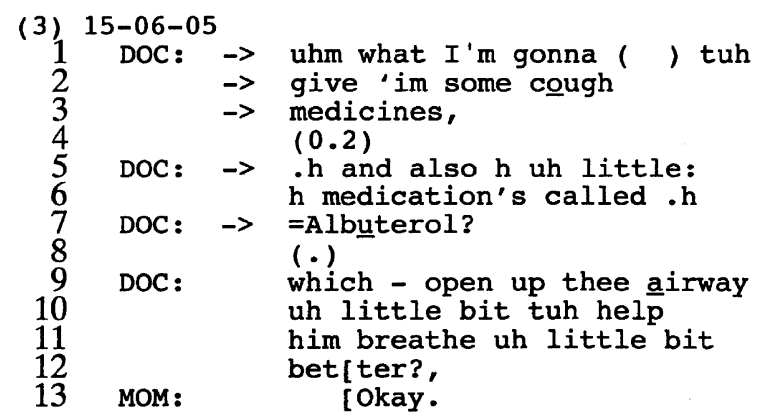

Similar to Extracts 1-2, here the physician affirmatively states what treatment the boy should be given: a cough medicine (lines 1-3) and a medication called Albuterol (lines 6-7). Also, like Extracts 1-2, the mother agrees to this recommendation with "Okay." in line 13 .

\footnotetext{
${ }^{6}$ To save space, the diagnosis is not always shown.
} 


\section{Recommendations against treatment}

In contrast to recommendations for treatment, physicians also format treatment recommendations as against particular treatment. These were much less common as an initial recommendation $(n=29){ }^{7} \mathrm{Re}-$ commendations that are formatted in this manner recommend against either a class of treatment or a particular treatment. For an example of the former, see Extract 4.

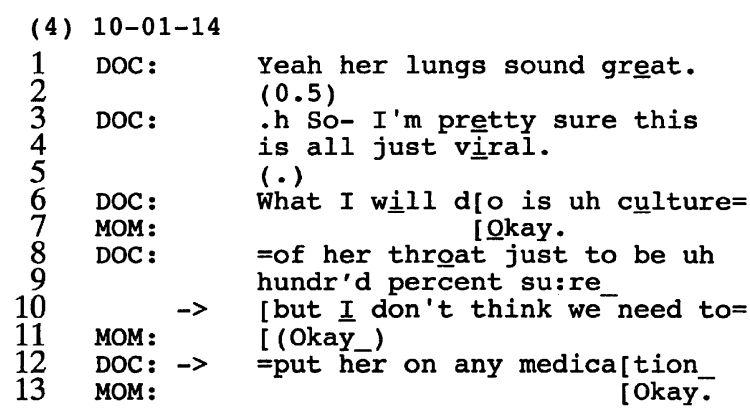

Similar to Extract 1, here the physician moves from a diagnosis in lines $1 / 3-4$ to a test recommendation (lines $6 / 8$ ) and to her treatment recommendation "I don't think we need to put her on any medication_" (lines 10/ 12). In contrast to the affirmative recommendation, here the physician announces what she recommends against ("any medication") rather than asserting what should be done. ${ }^{8}$ And, this is treated as complete by the parent at line 13 with "Okay".

Although physicians do recommend against larger classes of treatment, at least in the context of pediatric upper respiratory symptoms, it is more common that they recommend against particular medications, and antibiotics are the most common treatment that is recommended against. ${ }^{9}$ For instance, see Extract 5.

\section{(5) 15-06-07

$\begin{array}{llll}1 & \text { DOC: } & \rightarrow & \text { But in the meanti: :me no: } \\ 2 & & & \text { antibiotics or anything yet. } \\ 3 & \text { DOC: } & \text { Okay?, } \\ 4 & \text { MOM: } & \text { Yeah. }\end{array}$

In lines $1-2$, the physician names antibiotics using that as an instantiation of medication that is unnecessary at this time (with "or anything"). Also note that when acceptance of the treatment recommendation is not

\footnotetext{
${ }^{7}$ Note that the total number of recommendations for and against do not equal 309 because (1) physicians do not always offer a treatment recommendation, and (2) there were some cases where the format was not clearly of either variety.

${ }^{8}$ Even when the term physicians use is "medicine", "medication", or "treatment", this is often understood (at least in this medical context) to mean antibiotics (Stivers, 2000).

${ }^{9}$ Sudafed (over-the-counter) or prescription asthma medications are other things that are recommended against in this data set.
}

immediately forthcoming after line 2 , it is pursued by the physician in line 3 . This displays, at minimum, the doctor's orientation to the treatment having been completed at line 2. That said, it is quite common for physicians to address both what is and what is not needed for treatment in the course of an interaction. However, it is most common for physicians to address what is not needed prior to what is needed. That is, in 24/29 cases in which physicians stated an initial recommendation against particular treatment there was a subsequent recommendation for treatment. By contrast, when a physician initially recommends for particular treatment, it is relatively infrequent that they go on to provide a recommendation against particular treatment $(20 / 252)$.

This might suggest that recommendations against particular treatment are part of a larger structure that includes both a negative component and a positive component. This sort of a structure does exist but is quite rare, see Extract 6.

$\begin{array}{ll}\text { (6) } & 17-08-10 \\ 1 & \text { DOC: } \\ 2 & \text { DOC: } \\ 3 & \\ 4 & \text { MOM: } \\ 5 & \text { DOC: } \\ 6 & \\ 7 & \text { MOM: }\end{array}$

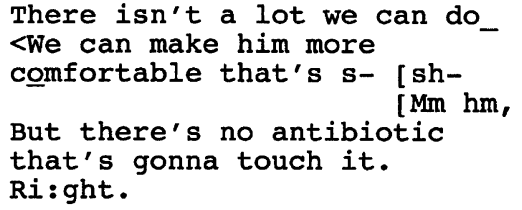

Here, the physician projects an affirmative treatment recommendation with "we can make him more comfortable" but goes on to deliver a recommendation against antibiotics. This recommendation format differs from the primary formats because it specifically is built to deal with both what is being recommended against and what is being recommended for in a single turn at talk. In part this is accomplished through the prosody which, although vulnerable to talk following "comfortable", is not built for turn transfer until the end of line 6 . This is not how recommendations are typically delivered (Stivers, in press).

Rather than being built from the outset as a multicomponent turn, both recommendations for particular treatment and recommendations against particular treatment are generally built as discrete units of talk. We saw some evidence for this in the cases examined thus far where the parent treated recommendation against treatment as complete (Extract 4) and doctor treated the recommendation against treatment as completed (Extract 5). Further, there appears to be an orientation by both parents and physicians to the relevance of uptake of the treatment recommendation at unit completion whether that recommendation is for or against a particular treatment (Stivers, in press). This leaves a question as to why recommendations against particular treatment are so commonly followed by recommendations for treatment. In short, the answer appears to be that this is because differential formats of 
uptake by parents following the alternative types of treatment recommendations. However, a full analysis of this will follow in subsequent sections.

As an initial illustration, see Extract 7. Here, we see a case where, following problematic uptake to a treatment recommendation against antibiotics, the doctor claims to have planned to discuss recommendations for other treatment. However, because the initial recommendation is hearably complete syntactically and prosodically after line 4, response is due. The father appears to be moving towards an aligning response (line 6).

$\begin{aligned} \text { (7) } & 38-34-05 \\ 1 & \text { DOC: } \\ 2 & \\ 3 & \\ 4 & \\ 5 & \text { BOY: } \\ 6 & \text { DAD: } \\ 7 & \text { DOC: } \\ 8 & \text { BOY: } \\ 9 & \text { DAD: } \\ 10 & \text { BOY: } \\ 11 & \text { DOC: } \\ 12 & \\ 13 & \text { DOC: }\end{aligned}$

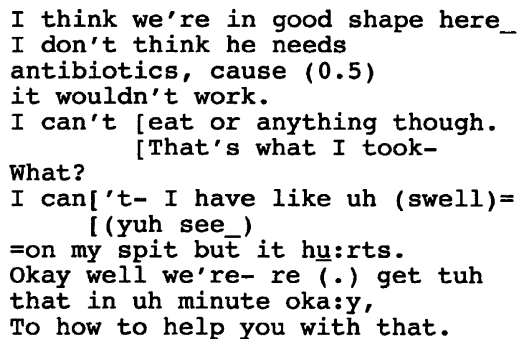

But before this is even begun, the boy resists the treatment recommendation (line 5). In line 8 , the boy further resists the doctor's prior treatment recommendation by offering a complaint. In this environment, offering a complaint hearably treats the problem he came in with as unsolved by the treatment recommendation that has been given. It is in this way that it resists the recommendation. Although the next section will explore resistance more fully, here note only that the doctor responds to the boy's resistance with a defense of his prior treatment recommendation as incomplete by referring to his plan to "get to that in uh minute". This case is interesting because we have the doctor's claim to a planned discussion of both what he recommends against and for. However, because the initial recommendation is delivered as a discrete turn, no second component has been projected and thus, this recommendation can be taken up - whether to accept or to resist-in its own right at this moment. Here, the physician does remedial work to deal with the boy's response to his treatment recommendation - to retroactively claim it was only a first recommendation. But note that this is the problem faced by the participants at each juncture of a treatment recommendation. The doctor may be complete and acceptance is due. If it is not forthcoming, this frequently shapes what happens subsequently.

As will be discussed further in the next section, parent responses differ depending on the format of the treatment recommendation. This is particularly consequential because the type of response a recommendation receives can shape how the physician proceeds with the visit (e.g., whether the treatment recommendation is continued and in what way it continues).
Parent resistance to recommendations against particular treatment

One behavior which has been shown to be highly consequential for whether or not a child receives antibiotics inappropriately or not is whether or not the parent resists a treatment recommendation (Stivers et al., 2003). Parent resistance is more common following recommendations against particular treatment. As mentioned earlier, physicians are oriented to the relevance of parent acceptance following the initial treatment recommendation. If none is forthcoming, and particularly if a treatment recommendation is met with active resistance (e.g., a challenge or query), physicians will do work to secure parent acceptance. As indicated in Fig. 1, often this work takes the form of alterations in the treatment plan, contingency plans for future treatment, reversals in treatment decisions (Stivers, in press) and leads to higher rates of inappropriate prescribing (Stivers et al., 2003). Thus, parent resistance is a particularly problematic response in this context, see Extract 8.

(8) 32-28-03

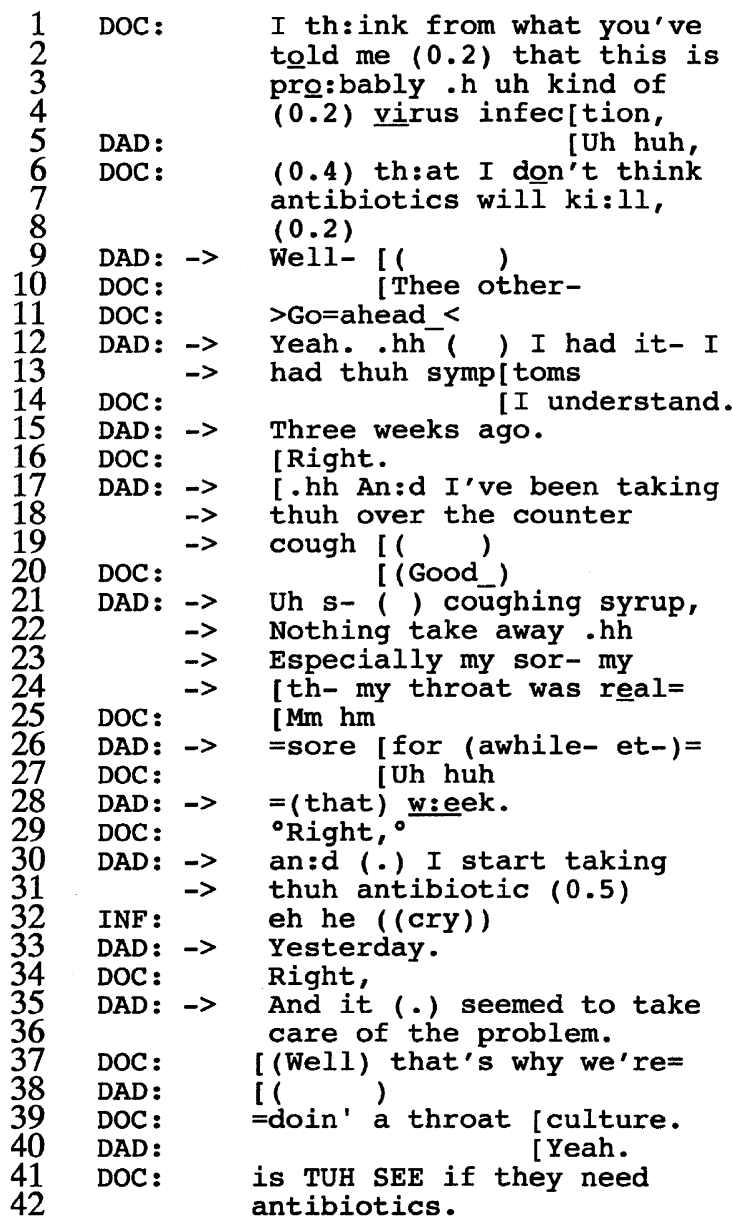


Here, following the diagnosis (lines 1-4), the physician offers a recommendation against antibiotics (lines 6-7). The parent does not immediately accept the recommendation (line 8), and then he begins active resistance. "Well" as in Extract 4, acts as a pre-disagreement token (Pomerantz, 1984). Following the physician's " $>$ Go $=$ ahead_<" (line 11), the father continues with active resistance in lines 12-13/15/17-19/21-24/ 26/28/30-31/33/35-36. This constitutes resistance because across this stretch of talk, the father builds a case for why antibiotics - the treatment the physician recommended against-may be effective: they were effective in treating a similar illness that the father recently had.

A second case is shown in Extract 9. Here, the physician offers a recommendation against antibiotics in lines 1-2. She pursues agreement to this proposal in line 4 , and receives this in line 5. However, immediately following the agreement, the mother inquires about further testing of the child which the doctor agrees with. Although the sequence is possibly closed at this point, and the physician initiates a move to closing in lines $12 / 14$ with an inquiry to the child about the visit not being "so scary,", in overlap, the mother initiates active resistance (lines 13/15).

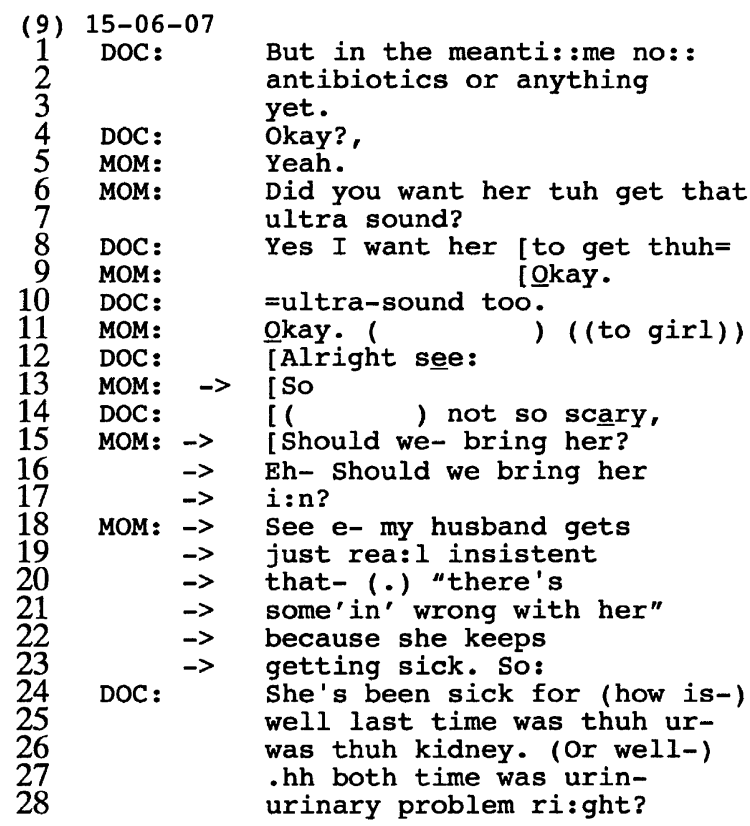

In line 15 , the mother begins her turn with another inquiry about future action: "Should we bring her i:n?" This is then immediately accounted for. This account constitutes resistance because it claims that the child is ill but also reflects the mother's own stance that the child should be brought in. This counters the recommendation the physician has just made which is against treatment despite the physician's recommendation for further testing. The physician addresses the mother's action as resistance by re-starting an investigation of the child's illness.

As mentioned earlier, it is not only how but also whether a parent responds that shapes whether and how physicians continue with treatment recommendations. For instance, see Extract 10.

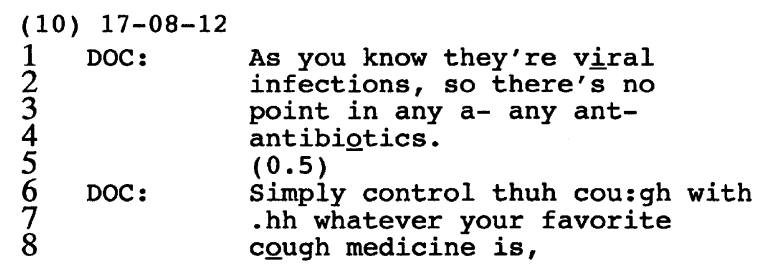

Here, the physician offers a recommendation against antibiotics in lines 2-4. It is only following a lack of uptake of this recommendation that a recommendation for other treatment is offered (lines 6-8). This pattern comprised the majority of the cases where a recommendation against treatment was followed by a recommendation for particular treatment.

What has been shown here is two-fold. First, when treatment recommendations are delivered negatively, resistance is more frequently engendered. One analysis that physicians appear to have as the basis for parent resistance is a lack of an affirmative or "sufficient" treatment recommendation. This is evidenced in that one-way physicians deal with a lack of uptake, or passive resistance, is to offer a recommendation for treatment. That this is a large component of what patients treat as comprising a sufficient treatment recommendation will be discussed in the next section.

\section{Treatment recommendations: orientations to what is sufficient}

Patients in the acute care context display an orientation to receiving a treatment recommendation as a relevant next activity following a diagnosis delivery (Robinson, 1999, 2003). One type of evidence for this is that when treatment is not immediately forthcoming, patients will pursue a treatment recommendation. In these data, this pattern is also present: parents ask about and thus pursue a treatment recommendation if no treatment recommendation is offered. However, more prominent is that some treatment recommendations are proposed by physicians but are responded 
to by parents as though they are insufficient. Thus, the absence of a treatment recommendation may be part of a larger normative orientation by parents to the relevance of having a sufficient treatment recommendation offered by physicians. This section will be concerned with providing evidence in support of this claim.

A treatment recommendation is generally treated as insufficient (not in the sequential sense but in the sense of providing a "solution") if it (1) fails to provide an affirmative action step, (2) is nonspecific, or (3) minimizes the significance of the problem. By contrast, a sufficient treatment recommendation asserts a specific next action step affirmatively and treats it as a wholly legitimate recommendation thereby treating the patient's problem as legitimate. All cases of recommendations against antibiotics fail to provide an affirmative next action step, and for this reason they are more likely to be resisted. Evidence that it is an affirmative action step that is at issue can be seen in that parents pursue this dimension of treatment following recommendations against particular treatment. For instance, see Extract 11. Here, following a recommendation against an antibiotic (lines 8-9), the parent inquires about a medication that she can provide (lines 14-16).

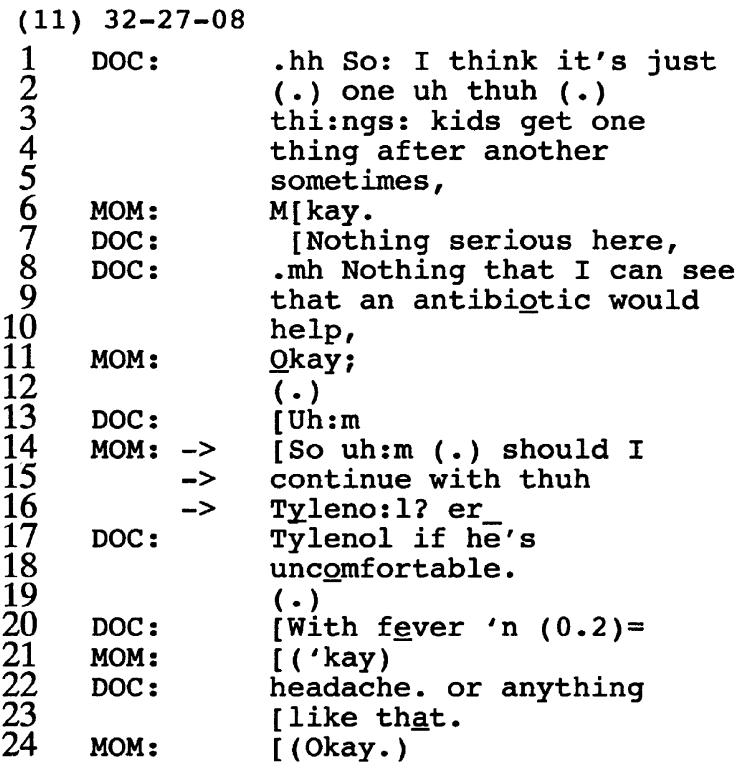

Although in some cases parents can be observed to actively advocate for antibiotics (Stivers, 2002a), in other cases resistance and other such behaviors may be rooted in a concern for receiving specific treatment. In this case, we can observe that the parent does not resist the lack of an antibiotic per se, but displays her concern and thus the root of this resistance to be the lack of an affirmative next action step. Also note that she does not resist the lack of a prescription since Tylenol is an over-the-counter recommendation. Rather, she pursues a concrete affirmative recommendation.

Another example is shown in Extract 12. After the physician recommends against an over-thecounter cold medication (lines 1-4), the mother inquires about another form of non-prescription treatment that she could offer her daughter (lines 11-12).

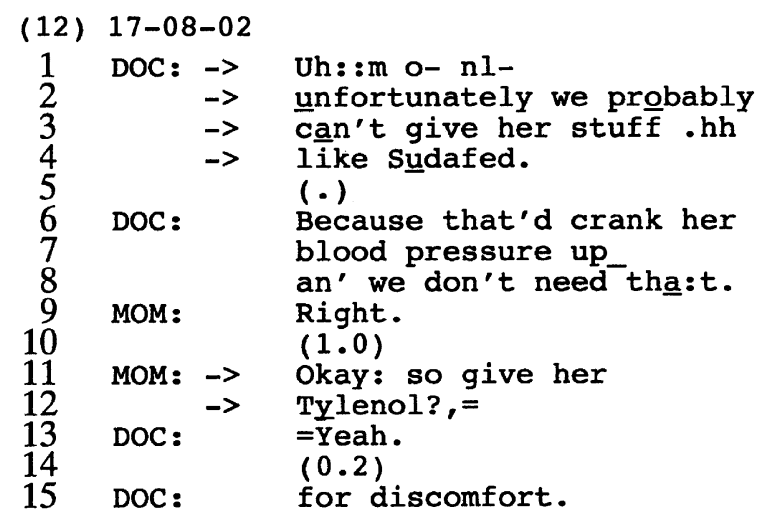

Again, the parent displays her concern to be not with the denial of Sudafed or with the non-recommendation of antibiotics but rather with what she can do for her child. As a final example, return to Extract 9. There, following a recommendation against antibiotics (lines 1-3), the mother inquires about a further diagnostic test (lines 6-7). Similar to asking about medications, asking about a test suggests that the mother is seeking an affirmative next action step. Note too that in all cases, the parents' questions are designed to prefer a "yes" answer, and thus to prefer the proposal of an affirmative course of action. ${ }^{10}$

Parents thus appear to be oriented not only to the relevance of receiving a treatment recommendation, but more specifically to receiving an affirmative next action step. Thus, parents appear oriented to a minimally sufficient treatment recommendation as necessarily including such an action step and without an affirmative next action step, parents treat the recommendation as insufficient. Recommendations against particular treatments, like the examples

\footnotetext{
${ }^{10}$ For an overview of preference in conversation see Heritage (1984a, b).
} 
shown earlier in this section, address the issue of necessary treatment for the child, but fail to propose an affirmative next action step and are problematic because they fail to adequately address their child's treatment.

Physicians can also be seen to be concerned about offering affirmative action steps for parents. For instance, see Extract 13. Here, the physician orients to "treatment" as not beginning until after he recommends against antibiotics.

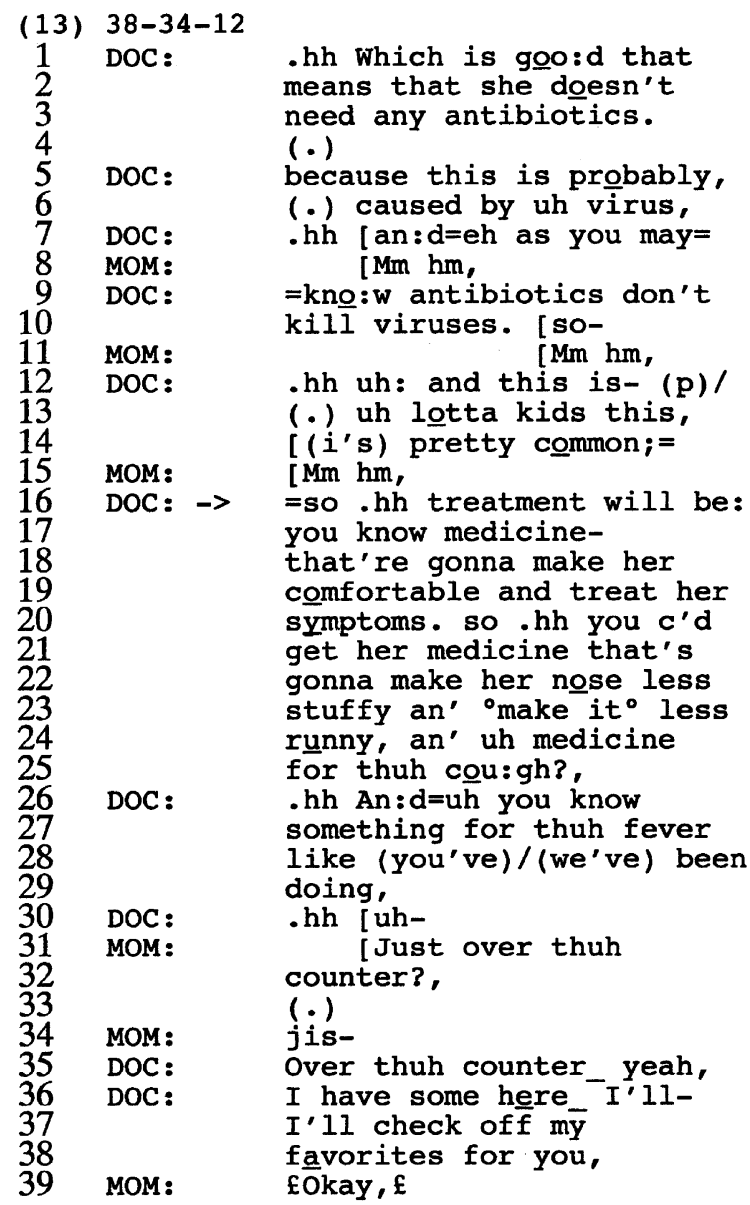

Here, although the doctor recommends against antibiotics in lines 1-3/5-7/9-10, he does not orient to that as "treatment". Rather, he contrasts that component and his recommendation for treatment with "Treatment will be: ..." (line 16). In this way, he differentiates between recommendations for and against a treatment.

Another example is shown in Extract 14. Here, having provided a diagnosis of a viral infection (line 1) and discussion of the mouth pain the child has been having (lines 2-8/10-12), the doctor indicates that there is no treatment when he states that the illness is "usually =h s:elf limited_" (lines 16-17). ${ }^{11}$

(14) 16-13-15

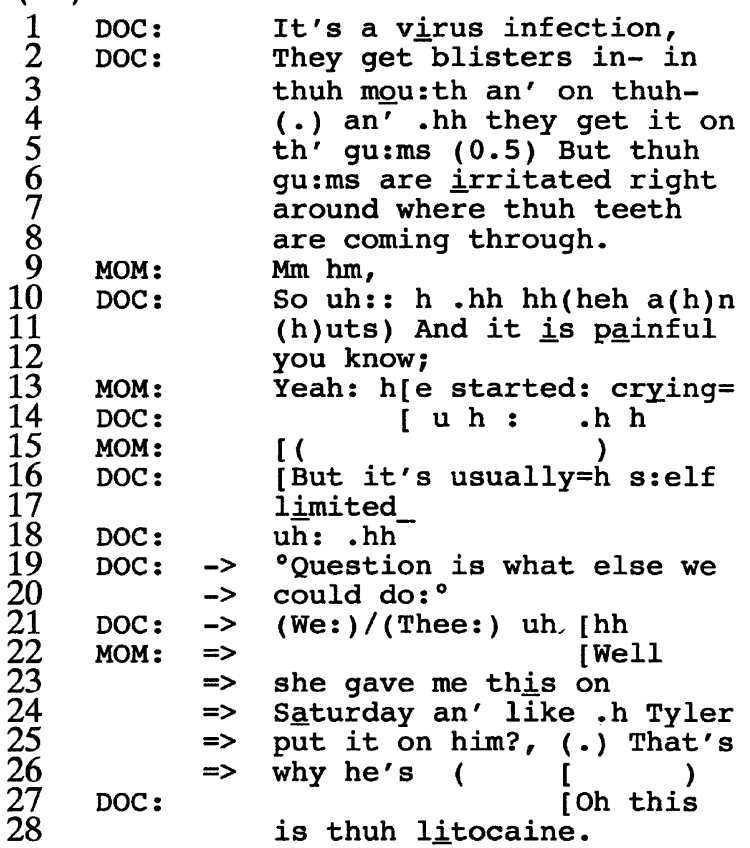

With no immediate uptake by the parent at line 18 , the physician then initiates a sotto voce search for affirmative treatment recommendations with " ${ }^{\circ}$ Question is what else we could do:" (lines 19-20), and an initiation of a possible recommendation (line 21). In response, the mother collaborates with the physician's search for a recommendation for particular treatment initiating a discussion of the medication provided by another physician the previous weekend (lines 22-26), and this is subsequently endorsed by the physician (data not shown). Such explicit orientations by physicians to the difference between the two formats for treatment recommendations are unusual in these data. However, as was discussed earlier, it is relatively uncommon, with the constellation of symptoms typically present in these visits, for a physician to offer only a recommendation against treatment and no additional recommendations. That is, if a physician offers a recommendation against a treatment, he/she typically also provides a recommendation for a treatment. But when the recommendation for a treatment is offered second, it is often the case that it has been interactionally generated (e.g., often by passive parent resistance) or is vulnerable to being heard that way (i.e., as a concession to a parent) as outlined earlier.

This section has shown that parents are concerned with treatments being sufficient and that one source of

\footnotetext{
${ }^{11}$ This is not a case of recommending against but is a case of no treatment (yet). It is shown here to illustrate the physician's orientation to the importance of an affirmative action step.
} 
insufficiency is the failure to provide an affirmative next action step. We observed that recommendations against a treatment generally fail on this dimension. We can now return to observe how parents respond to recommendations for particular treatments before returning to the other dimensions of treatment recommendation sufficiency.

\section{Parent responses to recommendations for particular treatments}

Among treatment recommendations for non-antibiotic treatment, recommendations for particular treatments are generally less likely to be resisted. For example, see Extract 15.

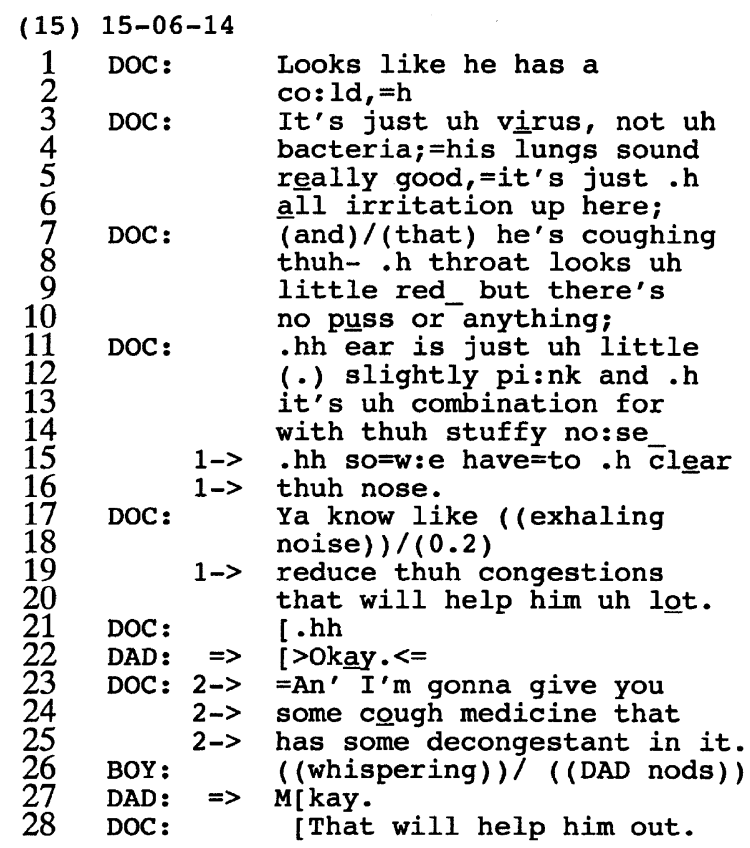

Here, following a diagnosis of a cold (lines 1-2) and the explication of the evidence for that diagnosis (lines 3-14), the physician goes on to affirmatively recommend non-antibiotic treatment: cough medicine. Besides being formatted affirmatively, the physician also formats her recommendation specifically-she recommends a type of cough medicine (lines 23-25). Earlier I mentioned that specificity was the second criteria of a sufficient treatment recommendation. Although the cough medicine may or may not turn out to be prescription, what appears to be important for whether or not resistance is likely to be engendered is that the recommendation is both specific and for a concrete next action step. Here, the cough medicine is not named, but the physician states that she is "gonna give you some" and specifies that it has "some decongestant in it". Both of these aspects of the turn indicate that she has in mind a particular medication and in this way she is being specific in her recommendation. This is subsequently accepted both visibly (line 26) and verbally (line 27).

A similar example was shown in Extract 1. Earlier we saw that the physician diagnosed a cold and recommended elevation and fluids in an affirmative formatted treatment recommendation. The physician's treatment recommendation offers the parent concrete affirmative action steps. Although she slightly minimizes her recommendation with "just" in line 23 , in general, her recommendation is formulated as an unmitigated positive announcement of what needs to be done in spite of the fact that the recommendation does not involve antibiotics. There is a moment of delay in acceptance (line 37 ) that leads to the physician's use of an increment to recomplete the recommendation (line 38) (Schegloff, 2000), but there is both acknowledgment at line 39 and full acceptance following the (possibly) responsive explanation of the illness and justification for the treatment (data not shown). A similar case is shown here in Extract 16.

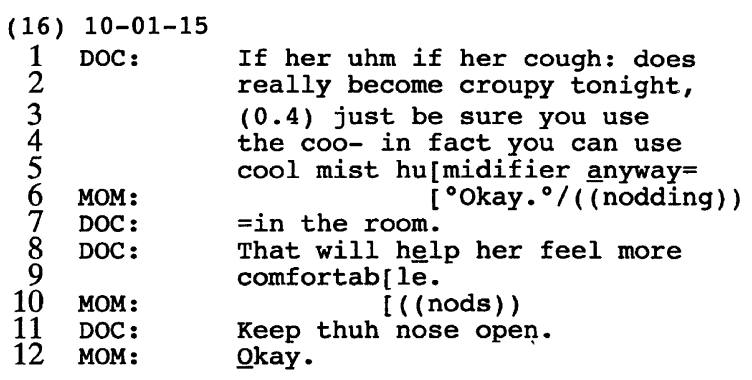

Here, again, the physician delivers her treatment recommendation beginning in line 1 . It is initially projected as a conditional with "if" but this is revised in line 4 with "in fact" and then in line 5 with "anyway". The recommendation is affirmative and specific - a cool mist humidifier.

In the last three cases we discussed, physicians satisfy the conditions outlined earlier for a sufficient treatment recommendation: They are affirmative, specific, nonminimized treatment recommendation. Because recommendations for treatment by definition satisfy the criteria of being affirmative, this may explain why they are less likely to be resisted. When recommendations for treatment are resisted, they typically fail on one of the latter two dimensions. That is, they typically either involve a vague/non-specific treatment recommendation or the physician minimizes either or both the child's 
diagnosis and/or the treatment recommendation. For example return to Extract 13. There, the physician recommended against antibiotics and for medicine for the girl's stuffy nose, cough, and fever. However, he failed to offer any specific treatment recommendation. At lines 31-32, the mother resists the recommendation with "just over the counter?,". In response, the physician offers to "check off my favorites for you," and goes on to provide a specific treatment plan. This revision is accepted by the parent (line 39) providing evidence that a physician's specificity is important to parents in their orientation to what constitutes a sufficient treatment recommendation.

The third dimension of whether a treatment recommendation is sufficient is minimization. Heritage \& Robinson (in press) shows that patients are concerned to have their medical visits treated by physicians as legitimate and display concern with this dimension in the way that they present their problems. This issue can also be observed in the way that patients respond to history taking questions (Stivers, 2000). In the treatment recommendation phase of the visit, offering prescription treatment such as antibiotics is one way that physicians treat patients as correct in having sought medical attention. They legitimize their visit through the prescription of medication. Offering no treatment is, conversely, understandable as delegitimizing the visit. In the context of URIs we have been discussing, physicians are vulnerable to being heard as delegitimizing the patient's visit when they do not prescribe antibiotics. However, when a treatment is affirmatively and specifically recommended, this may do work to counter this problem. By contrast, when physicians generalize to "whatever your favorite cough medicine is" or orient to the treatment as minimal or arbitrary, this creates or perhaps intensifies the problem parents face when the physician offers no treatment recommendation or recommends against a particular treatment. That is, with a minimized or vague treatment plan physicians both delegitimize the patient's visit and fail to provide a specific action step.

For instance, see Extract 17. Here, the physician does not initially receive acceptance when he recommends against antibiotics. He proceeds to recommend Robitussin affirmatively, but he presents his overall recommendation in a downgraded manner with "just". In contrast with the Extract 1 where one component of the treatment was downgraded, here the "just" downgrades and minimizes the entire recommendation. The recommendation here implies a contrast between stronger treatment and Robitussin thereby treating his recommendation of Robitussin as a minimal sort of treatment. The passive resistance in line 7 is addressed by the physician with one account for the lack of uptake - that the parent has tried this medicine already and found it to be inadequate.

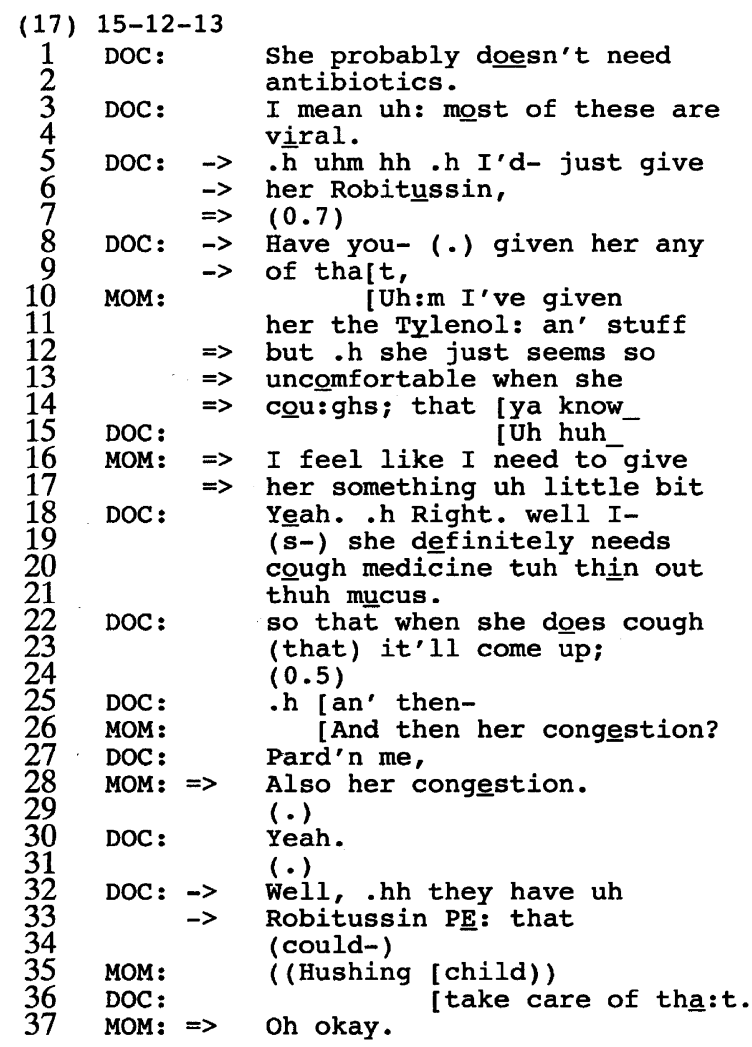

In response, the mother resists the treatment by asserting that her daughter is uncomfortable and needs "something a little bit" which idiomatically suggests that the likely next term was "stronger". The physician responds to the parent's resistance by agreeing that cough medicine is necessary, but he does not provide a specific responsive recommendation that indicates an upgrade on his prior recommendation. The mother then again resists the treatment by inquiring about treatment for her daughter's other symptom: congestion. With this inquiry, similar to other examples shown earlier, the mother conveys her perception that the physician's prior suggestion was insufficient. In response, the physician offers a specific recommendation "Robitussin PE" (lines 32-33), and this is accepted with "Oh okay." in line 37.

Thus far we have observed that physicians deliver non-antibiotic treatment recommendations as either for a treatment or against a treatment. We further observed that recommendations against a treatment were more likely to engender resistance. This was accounted for because this format fails to provide parents with an affirmative next action step as a solution to their child's problem. This was argued to be one key component to whether a recommendation was sufficient or not. We further observed that recommendations for a treatment 
could fail to be sufficient if they were non-specific or minimized the treatment.

\section{Treatment recommendation formats: implications for health care practitioners}

Given the above analyses, the puzzle may be how to deliver treatment recommendations at all. One option would be for physicians to always format their recommendations for treatment, never recommending against particular treatments. If negatively formatted treatment recommendations are more likely to engender parent resistance, perhaps there is no reason for them to be used at all. However, prior research suggests that physicians are more likely to recommend against antibiotics following particular parent behaviors that indicate they are seeking antibiotics such as offering a bacterial candidate diagnosis (Stivers, 2002b). In such contexts, recommending against antibiotics is an interactionally responsive, and thus potentially validating, behavior.

Also, when recommending against an antibiotic, physicians often provide an account for this recommendation. In doing so, physicians at the very least convey that they considered prescribing it and decided against it-something which may reassure parents who were concerned about the necessity of an antibiotic. In some cases, following a recommendation against particular treatment, physicians go on to explicitly provide education about why they are not prescribing the antibiotic. For instance, see Extract 18.

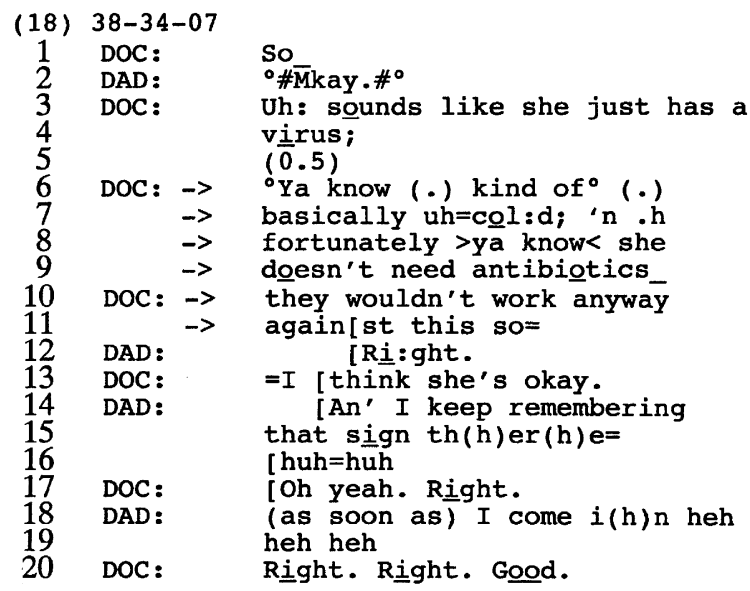

After offering his diagnosis in lines $1 / 3-4 / 6-7$, the physician recommends against antibiotics (lines 8-9). The physician then provides a rationale for this recommendation: "they wouldn't work anyway against this" (lines 10-11). Embedded in his rationale is "anyway" which treats a negotiation of antibiotics as somewhat pointless in the sense that although he is recommending against antibiotics, even if he provided them, they would not work for this illness. In response, the parent agrees and references a poster about antibiotics for viral illnesses that is on the wall of the examination room (lines 14-15/18).

Thus, recommendations against antibiotics provide physicians with a resource for communicating two important issues: (1) that their treatment recommendations for the children's problems are responsive to the parents' concerns of whether antibiotics were necessary; and (2) when antibiotics may not be appropriate in the treatment of upper respiratory tract infections.

Although specific interactions make relevant particular responsive behavior, in these data, physicians appeared most likely to secure parent acceptance and minimize parent resistance when they first offered a specific affirmatively formatted treatment recommendation. Although acceptance did not always follow immediately, physicians were more likely to secure acceptance following these recommendations. Among cases with parent acceptance and little or no resistance, recommendations against a treatment were typically positioned shortly after the recommendation for a treatment. For instance, see Extract 19 (the earlier portion was shown as Extract 15).

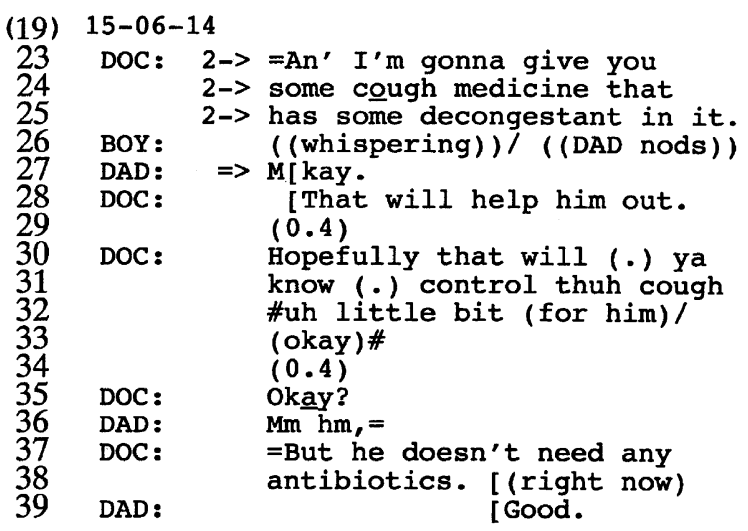

Here, as noted earlier, the physician first offers a specific treatment plan (see arrows 1 and 2) and secures agreement (see double arrows). Following that, she recommends against antibiotics (lines 37-38). In this position, the father positively assesses this recommendation (line 39), and the visit directly proceeds out of the activity of treatment recommendation.

A further argument for positioning recommendations against treatment as a second treatment proposal is that recommendations against antibiotics may serve as a further resource for the physician to advocate for their non-antibiotic treatment proposal. For instance, see 
Extract 20.

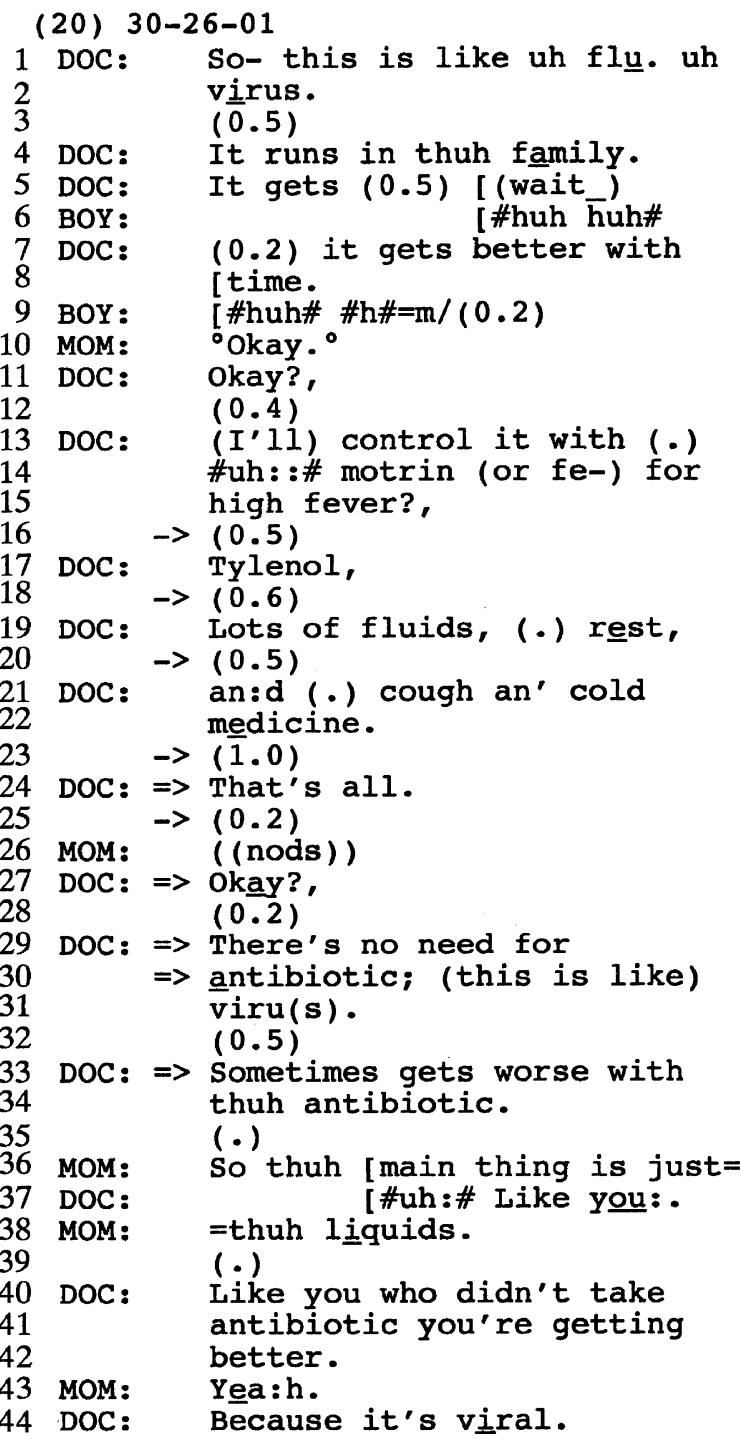

In this case, the physician implies no treatment with "it gets better with time" (lines 7-8). This is minimally accepted with a lowered volume "Ookay." (line 10). The low volume and the delay prior to the acknowledgment suggest hesitancy on the part of the parent, and it may be in response to this that the physician then shifts to more specific and affirmative treatment recommendations (lines 13-15/17/19/21-22). However, the mother does not accept any of the suggested treatment recommendation. Note that there is no active resistance from the mother, but she withholds alignment with any of the proposals (Stivers, in press). In line 21, the physician prefaces his possibly final recommendation with "and" and brings the list to strong final intonation; but acceptance is still not forthcoming from the mother.
Here, he recompletes his recommendation in line 24 with "That's all." which pursues parent uptake. In response, the parent offers a slightly delayed and minimal head nod. But following pursuit of a more overt acceptance in line 27 with "Okay?,", the parent offers nothing.

At this point the physician recommends against antibiotics (lines 29-30) and further states that it could make the child's illness worse (lines 33-34). Here, the mother seeks confirmation of one component of his recommendation and displays an orientation to the positively formatted recommendations that had been offered as she requests clarification of "the liquids" (lines 36/38). Here, we see that by invoking antibiotics, the physician may be able to address an underlying problem the parent has with the proposed treatment. That antibiotics are being oriented to as the barrier to activity closure is further evidenced by the physician's additional work to point out to the parent that in fact she is getting better without having taken antibiotics (lines 37/40-42). Thus, here, following an affirmative treatment recommendation, the recommendation against antibiotics does not engender resistance but may display the physician to have completed his recommendation and thus provide the physician with a resource for securing closure of the activity and of the visit.

This section thus proposes that when interactional circumstances support such an ordering, parents may be most receptive to non-antibiotic treatment recommendations when they are delivered such that specific recommendations for treatment are offered first followed by recommendations against particular treatment.

\section{Discussion}

This paper examined alternative practices that physicians have for delivering their treatment recommendations. Two main practices were identified for recommending treatment: either recommending for or against a medication. Parent behavior in response to these alternative delivery formats suggests several important points: (1) parents display an orientation to the relevance of an affirmative and specific treatment recommendation whether or not a recommendation against a particular treatment has been offered; (2) parents are more likely to resist a recommendation against particular treatment; and (3) parents are more likely to resist non-specific treatment recommendations even if offered affirmatively. These findings are significant because prior research has shown that when parents actively resist non-antibiotic treatment recommendations, physicians are more likely to perceive them as expecting antibiotics and consequently are more likely to inappropriately prescribe antibiotics (MangioneSmith et al., 1999; Stivers et al., 2003). This paper 
further showed that although recommendations that were formatted as against particular treatment were problematic in terms of engendering more parent resistance, they offered physicians a resource for (1) displaying responsiveness to earlier parent concerns about the need for particular medication; and (2) educating parents about when antibiotics are inappropriate and why. Thus, this paper suggests that physicians who offer specific, positively formulated treatment plans are more likely to secure parent acceptance, and following recommendations for a treatment, recommendations against a treatment are less likely to be interactionally problematic and can be useful both interactionally and for health education purposes.

This study is part of a growing tradition in communication and sociology which uses conversation analytic methods to identify physician and patient communication patterns that are recurrent and to analyze them for their function in the provider-patient interactional context (see Drew \& Heritage, 1992a; Heritage \& Maynard, in press for examples of such contributions). CA methods are particularly well suited to analyzing practitioner-patient behavior because they focus on how a current action embodies a type of reasoning and is visibly used and relied on by the participants. In this way, the imposition of analyst derived categories on interactional data is strictly resisted.

This methodology also lends itself well to subsequent quantitative investigations which attempt to test communication behavior associations with one another (Stivers, 2002b) or which test communication behavior associations with exogenous variables such as questionnaire responses (e.g., Mangione-Smith, Stivers, Elliott, McDonald, \& Heritage, 2003; Stivers et al., 2003) because CA methodology mandates a very precise operationalization of communication practices. Thus, as mentioned earlier, any coding of physician or parent/ patient behavior is done in such a way that it is true to the interactional reality of the participants rather than analytic constructs that may not be relevant for the participants. In this case, this reliance on participant behavior revealed a differential analysis of recommendations for and against particular treatment that can be used to inform medical goals of decreasing parent resistance and inappropriate antibiotic prescribing.

Coupled with quantitative methods, future studies should test associations between these different treatment recommendation delivery formats and such exogenous variables as parent satisfaction and inappropriate antibiotic prescribing. Also, future studies will need to test the hypothesis ventured here that physicians who design their treatment recommendations in such an order that affirmative specific recommendations for treatment preceded recommendations against particular treatment will be less likely to receive resistance and thus will be less likely to inappropriately prescribe antibiotics for viral upper respiratory tract infections.

\section{Acknowledgements}

A portion of this paper was presented at the International Communication Association Convention in San Diego, CA in May 2003 and at the National Communication Association Convention in Miami Beach, FL in November 2003. Data collection for this study was supported by Grant \#039189 from the Robert Wood Johnson Foundation.

\section{References}

Aronoff, S. C. (1996). Antimicrobials in children and the problem of drug resistance. American Family Physician, 54(1), 44.

Baquero, F., Baquero-Artigao, G., Canton, R., \& Garcia-Rey, C. (2002). Antibiotic consumption and resistance selection in Streptococcus pneumoniae. Journal of Antimicrobial Chemotherapy, 50(Suppl. C), 27-38.

Barden, L. S., Dowell, S. F., Schwartz, B., \& Lackey, C. (1998). Current attitudes regarding use of antimicrobial agents: Results from physicians' and parents' focus group discussions. Clinical Pediatrics, 37, 665-672.

Bell, N. (2002). Antibiotic resistance: The Iowa experience. American Journal of Managed Care, 8(11), 988-994.

Belongia, E. A., Sullivan, B. J., Chyou, P. H., Madagame, E., Reed, K. D., \& Schwartz, B. (2001). A community intervention trial to promote judicious antibiotic use and reduce penicillin-resistant Streptococcus pneumoniae carriage in children. Pediatrics, 108(3), 575-583.

Byrne, P. S., \& Long, B. E. L. (1976). Doctors talking to patients: A study of the verbal behaviours of doctors in the consultation. Exeter: Royal College of General Practitioners.

Cristino, J. M. (1999). Correlation between consumption of antimicrobials in humans and development of resistance in bacteria. International Journal of Antimicrobial Agents, 12(3), 199-202.

Dagan, R. (2000). Clinical significance of resistant organisms in otitis media. Pediatric Infectious Disease Journal, 19(4), 378-382.

Deeks, S. L., Palacio, R., Ruvinsky, R., Kertesz, D. A., Hortal, M., Rossi, A., Spika, J. S., \& DiFabio, J. L. (1999). Risk factors and course of illness among children with invasive penicillin-resistant Streptococcus pneumoniae. The Streptococcus pneumoniae Working Group. Pediatrics, 103(2), 409-413.

Drew, P., \& Heritage, J. (1992a). Talk at work. Cambridge: Cambridge University Press.

Drew, P., \& Heritage, J. (1992b). Analyzing talk at work: An introduction. In P. Drew, \& J. Heritage (Eds.), Talk at work (pp. 3-65). Cambridge: Cambridge University Press.

Feikin, D. R., Schuchat, A., Kolczak, M., Barrett, N. L., Harrison, L. H., Lefkowitz, L., McGeer, A., Farley, M. M., Vugia, D. J., Lexau, C., Stefonek, K. R., Patterson, J. E., \& 
Jorgensen, J. H. (2000). Mortality from invasive pneumococcal pneumonia in the era of antibiotic resistance, 1995-1997. American Journal of Public Health, 90(2), 223-229.

Finkelstein, J. A., Metlay, J., Davis, R. I., Rifas, S., Dowell, S. F., \& Platt, R. (2000). Antimicrobial use in defined populations of infants and young children. Archives of Pediatrics and Adolescent Medicine, 154, 395-400.

Friedland, I. R. (1995). Comparison of the response to antimicrobial therapy of penicillin-resistant and penicillin susceptible pneumococcal disease. Pediatric Infectious Diseases Journal, 14(10), 885-890.

Gomez, J., Banos, V., Ruiz Gomez, J., Herrero, F., Nunez, M. L., Canteras, M., \& Valdez, M. (1995). Clinical significance of pneumococcal bacteraemias in a general hospital: A prospective study 1989-1993. Journal of Antimicrobial Chemotherapy, 36(6), 1021-1030.

Gonzales, R., Malone, D. C., Maselli, J. H., \& Sande, M. A. (2001). Excessive antibiotic use for acute respiratory infections in the United States. Clinical Infectious Diseases, 33, 757-762.

Gonzalez, R., Steiner, J. F., \& Sande, M. A. (1997). Antibiotic prescribing for adults with colds, upper respiratory tract infections and bronchitis by ambulatory care physicians. Journal of the American Medical Association, 278(11), 901-904.

Gums, J. G. (2002). Assessing the impact of antimicrobial resistance. American Journal of Health System Pharmacy, 59(8 Suppl. 3), S4-S6.

Hamm, R., Hicks, R., \& Bemben, D. (1996). Antibiotics and respiratory infections: Are patients more satisfied when expectations are met? The Journal of Family Practice, 43, 56-62.

Heath, C. (1992). The delivery and reception of diagnosis and assessment in the general practice consultation. In P. Drew, \& J. Heritage (Eds.), Talk at work (pp. 235-267). Cambridge: Cambridge University Press.

Heritage, J. (1984a). A change-of-state token and aspects of its sequential placement. In J. M. Atkinson, \& J. Heritage (Eds.), Structures of social action (pp. 299-345). Cambridge: Cambridge University Press.

Heritage, J. (1984b). Garfinkel and ethnomethodology. Cambridge: Polity Press.

Heritage, J. \& Robinson (in press). Accounting for the visit: Giving reasons for seeking medical care. In: J. Heritage, \& D. Maynard (Eds.), Practicing medicine: Talk and action in primary-care encounters. Cambridge: Cambridge University Press.

Heritage, J., \& Maynard, D. (in press). Practicing medicine: Talk and action in primary-care encounters. Cambridge: Cambridge University Press.

Heritage, J., \& Sefi, S. (1992). Dilemmas of advice: Aspects of the delivery and reception of advice in interactions between health visitors and first time mothers. In P. Drew, \& J. Heritage (Eds.), Talk at work (pp. 359-417). Cambridge: Cambridge University Press.

Heritage, J., \& Sorjonen, M. -L. (1994). Constituting and maintaining activities across sequences: And-prefacing as a feature of question design. Language in Society, 23, 1-29.
Heritage, J., \& Stivers, T. (1999). Online commentary in acute medical visits: A method of shaping patient expectations. Social Science \& Medicine, 49, 1501-1517.

Holmberg, S. D., Solomon, S. L., \& Blake, P. A. (1987). Health and economic impacts of antimicrobial resistance. Reviews of Infectious Diseases, 9, 1065-1078.

Kaiser, L., Lew, D., Hirschel, B., Auckenthaler, R., Morabia, A., Heald, A., Benedict, P., Terrier, F., Wunderli, W., Matter, L., Germann, D., Voegeli, J., \& Stalder, H. (1996). Effects of antibiotic treatment in the subset of common-cold patients who have bacteria in nasopharyngeal secretions. The Lancet, 347, 1507-1510.

Mainous, A. G., Hueston, W. J., \& Clark, J. R. (1996). Antibiotics and upper respiratory infection: Do some folks think there is a cure for the common cold? The Journal of Family Practice, 42, 357-361.

Mangione-Smith, R., Elliott, M. N., Stivers, T., McDonald, L., Heritage, J., \& McGlynn, E. A. (2004). Racial/ethnic variation in parent expectations for antibiotics: Implications for public health Campaigns. Pediatrics, 113(5), e385-e394.

Mangione-Smith, R., McGlynn, E. A., Elliott, M. N., Krogstad, P., \& Brook, R. H. (1999). The relationship between perceived parental expectations and pediatrician antimicrobial prescribing behavior. Pediatrics, 103(4), 711-718.

Mangione-Smith, R., Stivers, T., Elliott, M. N., McDonald, L., \& Heritage, J. (2003). The relationship between online commentary use and prevention of inappropriate antibiotic prescribing by pediatricians. Social Science \& Medicine.

Maynard, D. W. (2003). Bad news, good news: Conversation order in everyday talk and clinical settings. Chicago, IL: University of Chicago.

McCaig, L., Besser, R. E., \& Hughes, J. M. (2002). Trends in antimicrobial prescribing rates for children and adolescents. Journal of the American Medical Association, 287(23), 3096-3102.

McCaig, L. F., \& Hughes, J. M. (1995). Trends in antimicrobial drug prescribing among office-based physicians in the United States. Journal of the American Medical Association, 273, 214-219.

Nava, J. M., Bella, F., Garau, J., Lite, J., Morera, M. A., Marti, C., Fontanals, D., Font, B., Pineda, V., Uriz, S., et al. (1994). Predictive factors for invasive disease due to penicillin-resistant Streptococcus pneumoniae: A populationbased study. Clinical Infectious Diseases, 19, 884-890.

Neu, H. C. (1992). The crisis in antibiotic resistance. Science, 257, 1064-1073.

Orr, P. H., Scherer, K., MacDonald, A., \& Moffatt, M. (1993). Randomized placebo controlled trials of antibiotics for acute bronchitis: A critical review of the literature. The Journal of Family Practice, 36(5), 507-512.

Palmer, D. A., \& Bauchner, H. (1997). Parents' and physicians' views on antibiotics. Pediatrics, 99(6), 862-863.

Pennie, R. A. (1998). Prospective study of antibiotic prescribing for children. Canadian Family Physician, 44, 1850-1856.

Peräkylä, A. (1998). Authority and accountability: The delivery of diagnosis in primary health care. Social Psychology Quarterly, 61(4), 301-320.

Pomerantz, A. (1984). Agreeing and disagreeing with assessments: Some features of preferred/dispreferred turn shapes. In J. M. Atkinson, \& J. Heritage (Eds.), Structures of social 
action: Studies in conversation analysis (pp. 57-101). Cambridge: Cambridge University Press.

Reichler, M. R., Allphin, A. A., Breiman, R. F., Schreiber, J. R., Arnold, J. E., McDougal, L. K., Facklam, R. R., Boxerbaum, B., May, D., Walton, R. O., et al. (1992). The spread of multiply resistant Streptococcus pneumoniae at a day care center in Ohio. Journal of Infectious Diseases, 166, 1346-1353.

Robinson, J. D., 1999. The organization of action and activity in primary-care, doctor-patient consultations. Unpublished doctoral dissertation. Los Angeles: University of California

Robinson, J. D. (2003). An interactional structure of medical activities during acute visits and its implications for patients' participation. Health Communication, 15(1), 27-57.

Rotbart, H. A., \& Hayden, F. G. (2000). Pilornavirus infections: A primer for the practitioner. Archives of Family Medicine, 9, 913-920.

Sacks, H. (1987). On the preferences for agreement and contiguity in sequences in conversation. In G. Button, \& J. R. E. Lee (Eds.), Talk and social organisation (pp. 54-69). Clevedon, England: Multilingual Matters.

Sanchez-Menegay, C., \& Stalder, H. (1994). Do physicians take into account patients expectations? Journal of General Internal Medicine, 9, 404-406.

Schegloff, E. A. (2000). On turns' possible completion, more or less: Increments and trail-offs. National communication association convention, Seattle, WA.

Schegloff, E. A. (in press). A primer for conversation analysis: sequence organization. Cambridge, England: Cambridge University Press.

Schwartz, B. (1999). Preventing the spread of antimicrobial resistance among bacterial respiratory pathogens in industrialized countries: The case for judicious antimicrobial use. Clinical Infectious Diseases, 28, 211-213.

Schwartz, R. H., Freij, B. J., Ziai, M., \& Sheridan, M. J. (1997). Antimicrobial prescribing for acute purulent rhinitis in children: A survey of pediatricians and family practitioners. Pediatric Infectious Disease Journal, 16, 185-190.

Stivers, T., 2000. Negotiating antibiotic treatment in pediatric care: The communication of preferences in physician-parent interaction. Unpublished doctoral dissertation. Los Angeles: UCLA.
Stivers, T. (2002a). Participating in decisions about treatment: Overt parent pressure for antibiotic medication in pediatric encounters. Social Science \& Medicine, 54(7), 1111-1130.

Stivers, T. (2002b). Symptoms only and candidate diagnoses: Presenting the problem in pediatric encounters. Health Communication, 14(3), 299-338.

Stivers, T. (in press). Parent resistance to physicians' treatment recommendations: One resource for initiating a negotiation of the treatment decision. Health Communication.

Stivers, T., Mangione-Smith, R., Elliott, M. N., McDonald, L., \& Heritage, J. (2003). Why do physicians think parents expect antibiotics? What parents report vs what physicians perceive. The Journal of Family Practice, 52(2), 140-148.

Todd, J. K., Todd, N., Damato, J., \& Todd, W. A. (1984). Bacteriology and treatment of purulent nasopharyngitis: A double blind, placebo-controlled evaluation. Pediatric Infectious Disease, 3(3), 226-232.

Vinson, D. C., \& Lutz, L. J. (1993). The effect of parental expectations on treatment of children with a cough: A report from the ASPN. The Journal of Family Practice, 37, 23-27.

Waitzkin, H. (1991). The politics of medical encounters. New Haven, CT: Yale University Press.

Wald, E. R., Guerra, N., \& Byers, C. (1991). Upper respiratory tract infections in young children: Duration of and frequency of complications. Pediatrics, 87, 129-133.

Watanabe, H., Sato, S., Kawakami, K., Watanabe, K., Oishi, K., Rikitomi, N., Ii, T., Ikeda, H., Sato, A., \& Nagatake, T. (2000). A comparative clinical study of pneumonia by penicillin-resistant and -sensitive Streptococcus pneumoniae in a community hospital. Respirology, 5(1), 59-64.

Whitney, C. G., Farley, M. M., Hadler, J., Harrison, L. H., Lexau, C., Reingold, A., Lefkowitz, L., Cieslak, P. R., Cetron, M., Zell, E. R., Jorgensen, J. H., \& Schuchat, A. (2000). Increasing prevalence of multidrug-resistant Streptococcus pneumoniae in the United States. New England Journal of Medicine, 343, 1917-1924.

Wise, R., Hart, T., Cars, O., Streulens, M., Helmuth, R., Huovinen, P., \& Sprenger, M. (1998). Antimicrobial resistance is a major threat to public health. British Medical Journal, 317, 609-610. 